\title{
La pérdida de objetividad en las noticias de los programas de infoentretenimiento en televisión
}

Carles Marín Lladó

Universidad Rey Juan Carlos

\section{Palabras clave}

Objetividad, noticias, infoentretenimiento, televisión

\section{Resumen}

Los géneros tradicionalmente informativos de televisión han ido cambiando a medida que los programas de infoentretenimiento se han asentado en todas las parrillas de televisión españolas, tanto en las cadenas públicas y privadas, como en las regionales. La espectacularización de estos espacios basados principalmente en la noticia, pero también en la entrevista y el reportaje, ha provocado una pérdida de la objetividad en sus contenidos. Sin duda nos encontramos en una nueva era de la televisión en la que géneros y formatos se están transformando definitivamente. La información con la opinión y los límites que separan el infoentretenimiento del espectáculo se mezclan con total asiduidad y, por supuesto, impunidad, para retornar después a la información más supuestamente estricta y rigurosa. 


\title{
The loss of objectivity on TV infotainment news programs
}

\section{Keywords}

Objectivity, news, infotainment, television

\begin{abstract}
The traditionally informative television genres have been changing as infotainment programs have settled on the grills of Spanish television, both in public and private networks, as well as the regional ones. The spectacularization of these programs based primarily on the news, but also in interviews and reports have caused a loss of objectivity in their content. There is no doubt we are in a new era where television genres and formats are definitely changing. Information, opinion and the boundaries that separate infotainment from show business get mixed frequently and with impunity, to return later to the most supposedly strict and rigorous information.
\end{abstract}

\begin{abstract}
Autor
Carles Marín [carles.marin@urjc.es] es doctor en Filología, especialidad lengua española y medios de comunicación audiovisuales. También es licenciado en Periodismo, en Filología Hispánica y en Filología Catalana. Es profesor titular de Periodismo informativo audiovisual en la Universidad Rey Juan Carlos y forma parte del Grupo de Estudios Avanzados de Comunicación (GEAC).
\end{abstract}




\section{Introducción}

En el año 2006 la televisión en España cumplió sus primeros cincuenta años de historia. Desde su nacimiento y hasta la llegada de las televisiones autonómicas, en el año 1983, Televisión Española (TVE) -con sus dos canales- fue cambiando a medida que la sociedad española iba dejando atrás la dictadura de Franco y se iba modernizando con la llegada de la libertad, con el asentamiento de las idiosincrasias plurinacionales y culturales, y por supuesto con el vertiginoso y expansivo recorrido de las nuevas tecnologías, que se iban aplicando a todos los órdenes de la vida de los españoles, tanto en el ámbito personal como en el profesional.

Precisamente, a partir de las TV autonómicas y de las privadas se mostraron otras formas de hacer y entender televisión: unas con un marcado carácter regional o sectorial, otras provocando una competencia real a TVE, que había crecido sin unos referentes de distanciamiento y competitividad profesionales conocidos hasta entonces. Con el nacimiento de Antena 3 Televisión, el 25 de enero de 1990, de Telecinco el 3 de marzo del mismo año, y de la televisión de pago Canal + sólo unos meses después: el 14 de septiembre, hubo una ruptura de la hegemonía de la reina de las audiencias que hasta aquel momento había ostentado TVE. Si en 1990 las cadenas privadas apenas representaban el 10\% de share, lo cierto es que cuatro años más tarde, esos mismos canales lograban ya el 44\% de la tarta de las audiencias televisivas (Marín, 2004; Oliva y Sitjà, 2007).

Desde 1990 hasta 2005 todas las televisiones vivieron una etapa de afianzamiento de las nuevas tecnologías, además de las batallas encarnizadas entre ellas por las audiencias, de la consolidación definitiva de las privadas, del nacimiento de los canales de pago por satélite (Canal Satélite Digital y Vía Digital en 1997), y de los canales temáticos de información: Canal 24 horas de TVE (1997) y CNN+ (1999), entre otros. También hubo propuestas que resultaron innovadoras en aquel momento, pero que fracasaron en poco tiempo. Es el caso de Quiero TV (2002), una plataforma de canales que congregó ofertas temáticas de video, música con calidad estereofónica, servicios interactivos, acceso a Internet, etc. (Cebrián, 2004b: 29).

Pero a pesar de que en estos más de cincuenta años de televisión hubo muchos avances que nos han conducido, sin duda, al medio que todos conocemos hoy en día, lo cierto es que la etapa iniciada en 2005 y culminada en 2010 fue la definitiva y también la más revolucionaria de la historia de la televisión y, por ende, de la fragmentación de las audiencias en nuestro país. En estos cinco años se pasó de una televisión convencional, generalista y analógica, a una televisión multimedia, temática y digital. También se asentaron definitivamente, y con éxito, las dos últimas televisiones generalistas de ámbito nacional: Cuatro, nacida el 7 de noviembre de 2005, y La Sexta, creada el 27 de marzo de 2006. La implantación definitiva de la Tecnología Digital Terrestre (TDT) en los hogares españoles fue una realidad en 2010 y, sin duda, acabó por definir y fragmentar la tarta de las audiencias en un claro proceso irreversible que llevó a una televisión de más 
variedad, aunque de menor calidad, tanto desde el punto de vista técnico, como de contenidos (Marín, 2006: 46-47). La crisis económica española (y también mundial) iniciada en 2008 contribuyó, en parte, a este fracaso de calidad que ha simbolizado hasta hoy la TDT.

Y en este afán de las empresas televisivas por conseguir el mayor número de puntos del share en una tarta que sigue siendo la misma, pero que se ha fragmentado en una gran variedad de canales, hay que hablar de los contenidos que se generan en sus parrillas de programación. De hecho, esta fragmentación ha provocado una ruptura de los géneros periodísticos audiovisuales tradicionales, así como de sus formatos, llegando a un punto en el que sus dos grandes áreas, el entretenimiento y la información, han terminado por fusionarse y, de este modo, crear otra área más. A esta tercera vía de contenidos televisivos se le conoce como infoentretenimiento, lo que ha provocado una nueva forma de entender el medio con una tipología de programas y formatos que triunfan actualmente en las parrillas de programación televisivas de nuestro país. Incluso se ha llegado a una hibridación entre los géneros tradicionales, promoviendo el documental dramatizado y el filme basado en hechos reales (Paget, 1998).

Veamos cómo ha sido el proceso transformador de los géneros que ha llevado a la situación televisiva actual en España.

\section{Transformación de los géneros audiovisuales tradicionales. El infoentre- tenimiento}

Mariano Cebrián Herreros distingue tres categorías para clasificar los géneros televisivos: los expresivos, los referenciales y los apelativos. Los Géneros expresivos y testimoniales son los que muestran el pensamiento, interpretación u opinión del autor, e incluso su propio testimonio. Los Géneros apelativos o dialógicos se basan en las opiniones de expertos o conocedores de un tema, mediante el diálogo que establecen con el periodista o persona que media con sus preguntas. Y por último, los Géneros referenciales o expositivos son los que ofrecen una versión claramente distanciada de los hechos, mediante sus exposiciones narrativas o descriptivas. En estos últimos cabe distinguir los subgéneros de la noticia, el reportaje, el informe periodístico, el documental y el docudrama (Cebrián Herreros, 1992: 35-43).

Por otra parte, en televisión se distinguen claramente dos tipos de programas: los informativos y los de entretenimiento. Aun así, existen espacios que incorporan parte de los dos. Para estos casos, el hilo conductor no es la noticia exclusivamente, sino la mayoría de los géneros televisivos más representativos o los géneros más utilizados, como el reportaje o la entrevista (Cebrián Herreros, 2004b: 147).

Precisamente de noticias están hechos los programas informativos, con el apoyo del reportaje y el informe periodístico. La misión de estos espacios es, principalmente, ofrecer al telespectador la actualidad de una forma puntual, facilitando 
las imágenes y sonidos que hagan posible una comprensión global. Los más conocidos son los telediarios. En ocasiones, la relación temporal que existe entre el momento en que se produce la noticia y el momento en que se transmite al telespectador es instantánea. Para ello, se conecta con un corresponsal de área, o un enviado especial, que cuenta lo que se está produciendo o lo que acaba de ocurrir.

Estos programas deben diferenciarse de un modo estricto de otros espacios llamados «De entretenimiento». Estos últimos tienen como objetivo distraer al telespectador y ofrecerle un tiempo de televisión divertido y ameno, a través de la entrevista, la crítica, el comentario, la encuesta, etc.

Hecha esta distinción, cabe preguntarse: ¿Es actualmente el informativo de televisión un programa propiamente dicho o se ha convertido en un espacio de entretenimiento, renunciando a su razón de ser como espacio de conocimiento, con una finalidad educativa y de calidad lingüística?

Lo cierto es que, cada vez más, la televisión en general se está convirtiendo en espectáculo, revirtiendo este efecto en todos los programas que ésta emite, ya sean información o entretenimiento. Todos los responsables de las cadenas de TV ven este medio como un negocio y, si bien los espacios de información siempre han servido para prestigiar el medio y ofrecer conocimiento, hoy en día estos programas se acercan más a una manera de hacer televisión para entretener, huyendo del género de la noticia, y acercándose más a la crónica, al comentario, a la crítica y, por ende, a la opinión. Sirvan como ejemplos los programas magacines matinales y los espacios de tertulia tan en boga en las televisiones de nuestro país, que incorporan la información en un tono más ligero y centran la noticia en su aspecto más social. Todo ello afecta al telespectador, puesto que éste no recibe la información estrictamente objetiva, es decir, en su estado más descriptivo. Es a partir de este momento cuando estaríamos hablando de un tipo de programas llamado: de infoentretenimiento, término que proviene de la palabra anglosajona infotainment y que se utiliza desde 1988 (Krüger, 1998: 637-664).

La pregunta retórica que cabe formularse es: ¿Son también los programas de información tradicional actuales espacios de infoentretenimiento?

\section{El infoentretenimento y la espectacularización de la televisión}

Si tenemos en cuenta que en España el 90\% de la población consume televisión y que de este porcentaje más del $50 \%$, es decir, más de 20 millones de personas sólo se informan a través de ella, podemos hacernos una idea de la importancia de este medio y de sus informativos, puesto que generan un gran impacto en la sociedad.

Por esta razón, en las últimas décadas, los empresarios de las cadenas se han dado cuenta del instrumento de poder que tienen en sus manos. Son conscientes de que pueden dirigir contenidos, interpretarlos y, si les conviene, ha- 
cer ver a la opinión pública que son necesarios cambiarlos por otros. A esta conciencia también se han sumado publicistas y políticos, ya que a unos les interesa por cuestiones económicas y a otros por razones electorales (Marín, 2003). A raíz de todo esto, y como fenómeno social, investigadores en comunicación han encontrado en estos formatos un buen material de estudio. Así, para José Alberto García Avilés el infoentretenimiento «alude a la tendencia de los medios a presentar la información como espectáculo, cuya función principal es la de servir de gancho para captar y mantener audiencia» (García, Avilés, 2007: 51). Por su parte, Bernardo Díaz Nosty y Teodoro León Gross alertan de la espectacularización de los informativos de televisión, a través de hechos noticiosos basados en sucesos y violencia demasiado sensacionalistas, que se programan en detrimento de otras noticias de corte político, internacional y económico, algo que había sido habitual hasta hace pocos años:

«El cambio de estrategia en los informativos se ha hecho visible, de manera progresiva, en la última década, de modo que han adquirido relieve informativo la violencia doméstica, la siniestralidad vial, los asuntos judiciales relacionados con crímenes pasionales y, en general, los sucesos, pero también el espacio de los espectáculos, los deportes y el mundo de la farándula [... Los espacios noticiosos de la televisión se han espectacularizado en los últimos años, lo que supone un empobrecimiento en sus contenidos, rigor y variedad temática. El fenómeno no es exclusivo de España y sigue una deriva que en los Estados Unidos, de forma mucho más acusada que en Europa, ha supuesto lo que se ha dado en llamar la tabloidización de los noticiarios, esto es, la traslación al espacio audiovisual de los códigos de la prensa sensacionalista. El fenómeno de la tabloidización orienta los contenidos, como se ha señalado, hacia las noticias de sucesos, escándalos, vida social y deportes, con registros menores de otros aspectos considerados, en términos periodísticos, como las verdaderas referencias informativas. Noticiarios que alimentan, en muchos casos, los escenarios, situaciones y personajes que aparecerán en programas de variedades, crónica rosa, nota roja y deportes. Esto es, los informativos sesgados hacia el sensacionalismo mueven al consumo de otras narraciones para-periodísticas, en las que ya se desvanecen los últimos rasgos de la función social del informador, los referentes éticos y otros valores distintivos de la profesión periodística» (Díaz Nosty, 2006: 22-23).

«Esta tabloidización temática se sostiene en todas las cadenas con un discurso al que sus conductores le imprimen un tono de formalidad periodística, vigor narrativo y credibilidad. Pero las debilidades de todos -anecdotización, centralismo informativo, falta de neutralidad con respecto a los intereses del emisor, pobreza de soluciones, escasa renovación en la edición vespertina...resultan patentes en un análisis incluso primario, desvelando la correspondencia con un público acrítico. La generalización de géneros es sólo teórica, ya que el comentario está ausente, la entrevista apenas aparece como recurso periodístico y las crónicas son el relato de los corresponsales. Estos informativos están lejos de ser un medio de referencia, no ya dominante, sino inductiva. El modelo comercial ha ganado por la mano, ya que esos informativos "se han convertido, en efecto, en auténticos magacines, programas contenedores en donde todo cabe, especialmente si es ajeno a la información relevante en el orden social y dispone de imágenes vistosas”. Ahí se define su claudicación, alejándose del prestigio informativo» (León Gross, 2006: 279).

Pero más allá de este alarmismo hecho público por investigadores y expandido, después, por los medios de comunicación social, lo cierto es que cabe preguntarse si la televisión se ha espectacularizado o simplemente ha evolucionado a través de los cambios de formatos. ¿Significa, para el caso que nos ocupa, que el infoentretenimiento, tanto en programas informativos como en magacines, ha superado su límite y se ha dejado llevar por el sensacionalismo más puro, perdiendo la objetividad que corresponde al género por excelencia que es la noticia? 
Tal y como asegura Kamp (1999: 78) en un plano global, «las televisiones han dado una vuelta de tuerca al tratamiento sensacionalista de los acontecimientos, en detrimento de asuntos más importantes». En el caso español, los programas informativos de televisión actuales están más apegados a la realidad, ofreciendo al telespectador más cercanía, a partir de informaciones de corte más humano, con una clara concienciación social. Aun así, los noticiarios ofrecen más sucesos y menos política, pero es a través de la denuncia social -con noticias que hablan de violencia de género, de acoso, de accidentes de tráfico, de violencia en general...- cuando el propio telespectador se da cuenta de que existen vías que le protegen y, gracias a ello, se anima a denunciar este tipo de actos que atentan contra su persona o contra personas de su entorno.

La televisión no nació como medio informativo, sino como un medio basado en el entretenimiento. Con el paso del tiempo y con el respaldo de la audiencia, este medio se ha convertido en la ventana de información más inmediata, que narra lo que sucede en nuestro entorno más cercano y también más lejano. Por lo tanto, y de acuerdo con esta evolución, los espacios de corte informativo de TV tienden hacia el infoentretenimiento, con la finalidad de no perder de vista su razón de ser, su idiosincrasia, en una sociedad cada vez más interesada por lo audiovisual. Aun así, el entretenimiento y la ficción televisiva, tan en boga en las parrillas de programación actual, han provocado por el efecto arrastre que el infoentretenimiento se convierta en puro entretenimiento disfrazado de información, lo que significa una pérdida de objetividad del propio profesional dedicado a la información en favor de la opinión. Surgen, de esta forma, pareceres, puntos de vista y conclusiones que el propio informador debería autocensurarse. En todo caso, sería el telespectador el que debería conformarse su opinión, pero solo a partir de los hechos que le transmite el profesional de la información.

\section{Objetivos y metodología. Descripción de la muestra. ¿El infoentreteni- miento en televisión degrada la objetividad de la noticia?}

En España, los espacios estrictamente de infoentretenimiento se programan en general en las cadenas generalistas de ámbito nacional ${ }^{1}$. Suelen ser macroespacios diarios que pueden durar hasta cuatro horas. Se engloban en un tipo de programas llamado magacín y se conforman a partir de los géneros de la noticia, el reportaje, la entrevista y la opinión, principalmente. La producción de estos espacios es costosa por las conexiones que se llevan a cabo en directo, a través de los enlaces vía satélite, y por el despliegue humano y técnico que hacen posible narrar la noticia al tiempo que esta ocurre.

Para llevar a cabo el presente estudio se ha hecho necesario analizar los principales magacines de ámbito estatal que se conforman como los espacios de infoentreteni-

1 Las televisiones autonómicas apenas ofrecen este tipo de espacios en la actualidad. Su alto coste de producción y su escasa aportación en el cómputo final del share diario hacen que sus directivos trasladen sus esfuerzos económicos en otras franjas más rentables, como el prime time. 
miento de mañana. El objetivo será conocer si estos espacios cruzan los límites que separan el infoentretenimiento del espectáculo televisivo más ortodoxo y, por lo tanto, pierden la objetividad en sus informaciones. ¿Estamos ante una nueva era de la televisión en la que géneros, formatos y público se transformarán definitivamente?

La metodología aplicada para este estudio se basa en el empleo de técnicas de investigación de carácter cualitativo: el análisis de contenido. La muestra utilizada está formada por los espacios matinales de infoentretenimiento y las cadenas que lo emiten. Se trata de Espejo público de Antena 3 televisión, Esta mañana de La 1 de TVE, La mirada crítica de Telecinco y Las mañanas de Cuatro en Cuatro. Estos programas se nutren de los géneros de la noticia, el reportaje y la entrevista (géneros referenciales) y de los géneros de opinión (apelativos).

Para contestar a la pregunta de este epígrafe se han visionado 80 espacios magacines ubicados de lunes a viernes durante cuatro semanas consecutivas (del 2 al 27 de febrero de 2009). Del análisis posterior se han extraído algunos de los fragmentos más representativos que corresponden a un mismo programa o a espacios diferentes con la finalidad de poder establecer las conclusiones a partir de tres hipótesis. Para poder conseguir este objetivo de una forma más clara si cabe, cada fragmento va acompañado de una sinopsis del espacio analizado y de una contextualización de la transcripción. No se trata, por lo tanto, de un análisis exhaustivo, sino de una muestra con valor representativo, cuyo resultado marca un camino de futuro para este campo de investigación.

A partir de la muestra descrita, se han establecido las siguientes hipótesis a través de un trabajo analítico de campo diacrónico:

- H1. El profesional de la información va más allá de su cometido al hurgar en lo morboso del hecho noticioso. Se consigue perder la objetividad con la que este tipo de informaciones debe redactarse.

- H2. El uso de adverbios, adjetivos, superlativos y comparativos por parte del redactor disfraza la información de puro entretenimiento, a la vez que incorpora opinión al género expositivo por excelencia: la noticia.

- H3. Los géneros y formatos de televisión se están transformando definitivamente. La información con la opinión y los límites que separan el infoentretenimiento del espectáculo se mezclan habitualmente. El telespectador asume el hecho noticioso sin el rigor y la objetividad propios de este tipo de periodismo.

\subsection{Análisis de la muestra}

\section{ANTENA 3: Espejo Público}

Se trata de un magacín basado en el infoentretenimiento y producido por los Servicios informativos de Antena3 Televisión. El eje central del programa es la actualidad y cuenta con conexiones en directo en el lugar de la noticia, con 
colaboradores, tertulias y entrevistas, y con la interacción del espectador, que opina sobre los temas que le afectan.

\section{FRAGMENTO 1}

A través de una conexión en directo, el reportero explica una estafa que afecta a unas seiscientas personas. Mediante una entrevista a una de las afectadas, el reportero intenta explicar al telespectador cómo ha vivido este hecho personalmente. Después de recabar los datos más relevantes de la noticia, el periodista hurga en lo más íntimo de la persona afectada, explicando al telespectador que la protagonista de la noticia intentó suicidarse a raíz de lo sucedido.

\section{ESTAFA POR PARTE DE DOS FINANCIERAS \\ $[\ldots]$}

Reportero: Hay muchos de los afectados que han denunciado amenazas, determinados tipos de presiones. En tu caso, el día que tuviste que deshacerte de tu vivienda fue absolutamente traumático, estuviste a punto de SUICIDARTE... Es muy serio, ¿eh?

Afectada: Me quedé, me quedé... Ves que has estado luchando y que pierdes todo por 13.000 euros... entonces me fui a las vías del tren.

Reportero: Como ella hay centenares de afectados. Todos ellos están poniendo denuncias en estos momentos. Hay que recordar que la investigación está abierta y que de momento hay tres personas detenidas: un responsable de una financiera, un director de una sucursal bancaria y uno de los notarios que, supuestamente, estaban compinchados.

$[\ldots]$

\section{FRAGMENTO 2}

A través de una conexión en directo, la reportera explica el juicio que se lleva a cabo contra un sacerdote que presuntamente abusó sexualmente de diez niñas. Una de las madres afectadas explica todos los detalles de su historia. La reportera hurga en lo más morboso de los hechos, preguntando a la madre detalles que sobrepasan la finalidad de la entrevista: conocer lo sucedido en su sentido informativo más objetivo, basado solo en hechos.

Un periodista y colaborador del programa opina libremente sobre el tema e incluso se atreve a aportar información que liga a esa madre y al presunto pederasta para hacer un juicio de valores que poco tiene que ver con el objetivo primitivo de la noticia.

\section{JUICIO A UN PRESUNTO SACERDOTE PEDERASTA}

Reportera: En el año 2006, este cura fue acusado de haber abusado sexualmente de una chica disminuida psíquica. La joven tenía 24 años, con una edad mental de siete. Este hombre abusó de ella en la Parroquia de Igualada, convenciéndola para poder hacerle los tocamientos a cambio de una bolsa de patatas fritas. Por aquel entonces, en el año 2007, el juez lo condena a dos años de prisión, pero el cura no va a la cárcel. De hecho, sigue en activo. Ahora, en la Audiencia de Barcelona se le está juzgando por haber realizado tocamientos a 
unas diez niñas. Hoy está con nosotros Sonia, que es la mamá de una de las niñas que abusó. ¿Qué tal está la pequeña?

Madre: Pues mi pequeña actualmente está bien, pero se pone muy nerviosa cada vez que se le tiene que llamar para juzgados y declaraciones. Ella ahora está un poco nerviosa.

Reportera: Ella está ahora aquí. Va a declarar...

Madre: Ella tendrá que declarar. No lo va a ver [al agresor]... Habrá mamparas. Reportera: No quiere ni verlo...

Madre: No quiere verlo para nada.

Reportera: ¿Qué era lo que le hacía este hombre?

Madre: Este hombre la tocaba en las clases de religión. La sentaba encima de él. Le tocaba la espalda, el culete y parte de la vulveta. Le metía las manos dentro de la braguita y cuando la niña intentaba levantarse, la volvía a coger, y entonces era cuando le susurraba al oído: «No le digas nada a tus padres, que tus padres te van a pegar».

Reportera: ¿Cuánto tiempo duró esto, Sonia?

Madre: Por lo que me dice mi niña, cinco o seis meses...

Repotera:_Y había más niñas con ella?

Madre: Sí. Cuando mi niña me comentó lo que le había hecho este individuo me comentó que había otra niña con ella...

Reportera: $\underline{Y}$ lo que es curioso Susanna [Griso], es que cuando eres consciente de esto y vas a protestar a la dirección del colegio, al parecer ya conocían que este señor era un pederasta. ¿Por qué permitieron que siguiera dando clases?

Madre: Sí que lo sabían... En mi caso, cuando yo fui a protestar, ya le habían echado...

FRAGMENTO 3

Una periodista explica la última portada de la revista Vogue. La opinión, a veces desagradable, y los comentarios soeces de los periodistas-tertulianos restan objetividad a la información, dándole un tono de espectáculo y alejándolo del infoentretenimiento entendido como tal.

\section{REPORTAJE DE MICHELLE OBAMA EN LA REVISTA VOGUE}

Copresentadora en plató: Hay una señora todavía más fotografiada, y más que lo a va ser... Me refiero a Michelle Obama. Se está convirtiendo en un icono para los norteamericanos y yo creo que para todo el planeta, y ya es portada el mes que viene para la revista VOGUE:

Copresentador en plató (Albert Castillón): ¡i¡Uau!!!

Copresentadora en plató: Ahí la veis. Impresionante, vestida de magenta, la primera dama ha recibido a los fotógrafos de Vogue... En fotos interiores, la vemos trabajando:

Copresentador: Un poco al estilo Soraya [Sáenz de Santamaría], ¿verdad? Copresentadora en plató: Pues no sé qué decirte... La ropa que lleva en el reportaje es ropa propia, de su armario...

Copresentador: ¿Y cómo le han disimulado las cartucheras, te das cuenta? 
Copresentadora en plató: Es una mujer que mide 1,80... No te metas con ella... Es verdad que puede tener un poquito de photoshop... Ya estamos acostumbrados... $[\ldots]$

Presentadora: No me ha gustado el comentario de las cartucheras, Albert... Yo creo que Michelle Obama es una mujer rotunda [hace gestos], contundente... Copresentador: ¿Qué hay de malo, a mí me gustan las mujeres con curvas? Presentadora: Si tuviese cartucheras, que no se las veo... oye, pues ¡Chapeau! Copresentador: ¿Cómo que no se las ves?

Presentadora: No...

Copresentador: Son inmensas...

Presentadora: ¡Qué va...!

FRAGMENTO 4

En una conexión en directo, una mujer narra cómo su ex pareja la raptó e intentó estrangularla. El periodista-colaborador del programa anima al testimonio a contar más detalles de los hechos que transcienden la información y se refugian en el espectáculo televisivo.

\section{RAPTO Y MALOSTRATOS A UNA MUJER}

Mujer: Hacía dos años que había terminado nuestra relación y él andaba averiguando sobre mí... Yo tenía mucho miedo cuando le veía... Me llevó hasta el sitio donde pasaron los hechos.

[Primer plano de la mujer maltrada. La imagen enseña un moratón en su ojo derecho].

Empezó a darme golpes y golpes. Me ponía el cinturón del coche... Me quería estrangular, me apretaba y me asfixiaba... Me daba muchos golpes, muchos golpes en la boca del estómago que me quitaba la respiración... Por la espalda... Metió la mano por debajo de su asiento y sacó una navaja muy grande. Me decía: Mira lo que tengo para ti. Con esto, hoy voy a acabar contigo, porque hoy es tu último día... Presentadora: ¡Qué horror lo que está usted describiendo! y, en fin... iqué serenidad...! Este hombre está detenido, espero... ¿no?

Mujer: Está en prisión preventiva...

Presentadora: Su gran temor es que no siga ahí durante mucho tiempo...

Mujer: No lo sé...

Copresentador: Duró una hora y media el calvario. ¿Cómo logró usted salir de ese coche y cómo decidió tirarse por un puente hacia un río a una altura considerable?

Mujer: Yo le dije que lo seguía amando, que no me hiciera daño. Y él me dijo que eso era mentira... Luego le dije que quería orinar, que por favor me ayudara. Me dijo: «Orínate aquí mismo, si me da igual». Y después de eso cedió abrirme la puerta, sosteniéndome la mano, y yo le decía que no podía abrirme la cremallera, porque me tenía agarrada la mano. Él se dio la vuelta por el otro lado para ayudarme a abrirme la cremallera y fue cuando me lancé al abismo del río... Nadé mucho, mucho... y logré salir al otro lado... Vi un ganadero, que llamó a la Guardia Civil... Este señor fue mi ángel de la guarda... Me dio calor... 


\section{TVE 1: Esta mañana}

Programa magacín basado en el infoentretenimiento y confeccionado con un tipo de periodismo social, a la vez que ameno. Se trata de un espacio cuyo propósito es informar y entretener a través de conexiones en directo en el lugar donde se produce la noticia.

\section{FRAGMENTO 5}

A través de una conexión en directo, la presentadora del programa habla con los padres de la joven Marta del Castillo, desaparecida en Sevilla en enero de 2009. La entrevista se lleva a cabo unos días antes de que el presunto autor del asesinato confesara los hechos a la policía. Las preguntas de la presentadora rebasan lo informativo y se convierte en espectáculo. El suceso se transforma, por lo tanto, en una noticia con el morbo como hilo conductor.

\section{DESAPARICIÓN DE MARTA DEL CASTILLO}

Presentadora: Ya son 20 días sin Marta. 20 días de calvario para una familia sevillana que no deja de buscar. Antonio y Eva, padres de Marta, ¡muy buenos días...! ¿Cómo estáis?

Padres: Desesperados.

Presentadora: Desesperados. Tres semanas ya [con voz plana]. La policía ha intensificado ya [la búsqueda] en algunos puntos más concretos...

Cuando veis que en las últimas horas, de repente, se intensifica esa búsqueda, a orillas del Guadalquivir, cerca de Camas donde vivía el chichito que salía antes con Marta... ¿qué pensáis?, ¿qué sospecháis?

Padres: Que se podía haber hecho antes.

Presentadora: ¿Por qué?

Padres: Porque llevamos tres semanas buscando...

Presentadora: Pero ¿vosotros sospechabais que tuviera que ver con la localidad de Camas?

Padres: Sí, porque el chico se movía por allí y fue el último que la vio... y tenía amistades por allí.

Presentadora: Nos ha sorprendido saber que este chico, además, vive ahora con su novia de 14 años, que está embarazada. ¿Vosotros lo sabíais? ¿Os ha sorprendido también?

$[\ldots]$

Presentadora: Os veo además con una cara de agotamiento..., razonable después de estos 21 días. ¿Qué está haciendo la familia aparte de la policía? $[\ldots]$

\section{FRAGMENTO 6}

Sigue la conexión del fragmento anterior. La presentadora enseña a los padres de la joven desaparecida las movilizaciones de los amigos de su hija. Unos compañeros de clase leen uno de los comunicados que han escrito. Mientras tanto, el programa muestra los rostros y las consiguientes reacciones de los padres. 


\section{DESAPARICIÓN DE MARTA CASTILLO}

Presentadora: La familia convoca concentraciones, se sigue movilizando... Hoy los amigos de Marta se han movilizado. Lo están haciendo desde las 11 de la mañana. Antonio y Eva [padres de la joven desaparecida], yo quiero que veáis esta imágenes de la última concentración y que escuchéis lo que dicen los amigos de vuestra hija...

Total amiga: ¡Marta! Queremos que aparezcas. Queremos que vuelvas a estar con nosotros, con tu clase, tu colegio, tus amigos [en catch, cara del padre de Marta], porque sabes que siempre estaremos contigo. No te mereces esto. Ni ninguno de nosotros, y mucho menos tu familia, la que siempre te apoyó en los momentos buenos y malos, quienes siempre te han avudado. En nombre de todos nosotros..., sabes que te echamos de menos, [se abre plano de la imagen del padre de Marta en catch para que salga también la madre de la joven desaparecida] que vemos todos los días esta silla, tu silla vacía, y no podemos dejar de pensar, de preocuparnos por ti, de preguntarnos: ¿dónde estarás?

Total amigo: ¡Esperanza! ¡Tú que puedes! Dile que guíe a la estrella de la niña que buscamos, para que el Domingo de Ramos esté en el puente con ella. Marta, queremos que vuelvas.

$[\ldots]$

Presentadora (después de los totales): Eran los amigos de vuestra hija... ¿Qué es lo que más teméis en este momento... Eva?

Madre: (Entre lágrimas) ¡Que no aparezca!

Presentadora: ¿Que no aparezca! Decíais en una entrevista hace poco que lo que no podríais soportar es que se dejase de buscar a Marta...

Madre: (Entre lágrimas) Sí... Me moriría, me moriría...

$[\ldots]$

\section{TELECINCO: La mirada crítica}

Se trata de un espacio de tertulia y opinión, basado en la actualidad política, el estudio de la realidad económica y social, las entrevistas, las noticias y los reportajes de máximo interés informativo diario.

\section{FRAGMENTO 7}

La presentadora del programa introduce dos reportajes sobre el sentir del pueblo sevillano ante la confesión del presunto asesino de la joven sevillana Marta del Castillo.

Las piezas incluyen el testimonio de una niña de 14 años, expareja del presunto asesino confeso.

DESAPARICIÓN DE MARTA CASTILLO. Confesión de los presuntos asesinos. Presentadora: Vamos a ocuparnos ahora de lo que sienten en estos momentos los padres de Marta. Como pueden imaginar, la confesión del chico les ha caído como una auténtica losa, porque albergaban esperanzas. Su padre nos lo decía así, cuando hablábamos con él aquí, en La Mirada Crítica. Ahora no salen de 
casa, una casa que se ha convertido en un altar por Marta. Los sevillanos no dejan de llevar velas, de dejar mensajes, y cuando se les pregunta... responden con mucha rabia, pidiendo justicia.

$[\ldots]$

Presentadora: Pero uno de los testimonios que más nos ha llamado la atención, que más nos ha impactado, es el de la chica -la niña podríamos decir, porque tiene 14 años- que fue la última novia de Miguel. Ella y su madre han contado a los periodistas la actitud que tuvo Miguel desde el primer momento. No les negó en ningún momento que tuviera algo que ver con la desaparición de Marta, ni con su muerte. Ahora, madre e hija se arrepienten de haber dado cobijo a un presunto criminal...

Total niña 14 años: [pregunta de una periodista: ¿Tú pensabas que podría ser él?]

Para nada... Hasta hace dos o tres días yo no he levantado cabeza... Sé que él es el asesino y no me lo creo... Conmigo nunca ha sido agresivo. Ha sido muy cariñoso... Nunca ha demostrado ser lo que es...

Cuatro: Las mañanas de Cuatro

Se trata de un magacín que realiza un análisis de la información diaria (conexiones en directo en el lugar de los hechos), prestando una especial atención a su mesa política, donde distintos periodistas discuten los temas relacionados con la política de la jornada.

\section{FRAGMENTO 8}

La reportera del programa habla del estado de salud de los padres de la joven sevillana Marta del Castillo. La directora y presentadora del espacio pregunta a la reportera qué ambiente se respira en el colegio donde iba la joven. La reportera incluye totales de sus compañeras (de espaldas) con preguntas que, una vez más, se basan en lo más íntimo y personal, restándole credibilidad informativa al hecho por su deliberada asociación a lo morboso. Se convierte, de este modo, en espectáculo televisivo.

DESAPARICIÓN DE MARTA CASTILLO. Reacciones a la confesión del presunto asesino.

Reportera en directo: Como os comentábamos, todo el barrio está conmocionado. Desde primera hora de la mañana ha sido incesante la llegada de gente que ha venido aquí a recordar a Marta de alguna manera. Su madre, Eva, continúa sedada, y su padre está muy nervioso, está cansadísimo, tremendamente cansado, pero por primera vez hoy ha atendido a los medios de comunicación y ha podido hablar sin salir de su casa desde la que están recluidos todos desde hace tres días, desde que se enteraron de la terrible noticia.

[Rótulo: Sevilla conmocionada por el espeluznante asesinato de marta]. Presentadora: Sé que has estado también en el colegio donde estudiaba Marta. ¿Qué ambiente había allí? ¿Qué te has encontrado?

Reportera: Hoy no va a ser un día como los demás. La gente está tremendamente impactada. Hemos hablado con la gente del colegio, por si iban a organizar 
alguna actividad. De momento lo van a pensar a lo largo de la jornada de hoy, pero sí que es cierto que hemos hablado con algunas de sus compañeras y eso es lo que nos contaban...

Total de la compañera de colegio: No nos lo creíamos ni nada...

Reportera: ...(hov) es el primer día de colegio, después de que os enterarais de la noticia. Me imagino que es muy duro para vosotros...

Total de la compañera de colegio: Durísimo. Hay gente que no ha venido, que no ha podido levantarse... No nos lo creemos ni nada... Hay que tener la sangre fría para hacer eso...

\section{FRAGMENTO 9}

La presentadora del programa entrevista al tío de Marta del Castillo, diciéndole que le acompaña en el sentimiento. Todavía no ha sido hallado el cadáver.

También hay una conexión en directo con la casa de la víctima en Sevilla. Se explica por qué hay una ambulancia en la casa. Han tenido que atender a la abuela paterna.

DESAPARICIÓN DE MARTA CASTILLO. Confesión de los presuntos asesinos. Presentadora: Enseguida tenemos que volver a Sevilla. Vamos a hablar de Marta del Castillo... Quiero agradecer especialmente a Javier, el tío de Marta, que esté con nosotros. Primero [quiero] decirle que le acompañamos a la familia en el sentimiento, y que sabemos que está agotado. Me imagino que psicológicamente agotado y en todos los aspectos. ¿Cómo está la familia en esos momentos? $[\ldots]$

Presentadora: Nos vamos a Sevilla... Teresa, cuéntanos. Sigues en la casa de Marta, no?

Reportera: Continuamos en el barrio de Tartesos en la calle Argantonio número 3 y tenemos una última hora. Como podéis ver, esto continúa lleno de curiosos, de gente que quiere venir a arropar a la familia, pero también vemos al fondo una ambulancia. $Y$ es que hace escasos 15 minutos ha tenido que acercarse una ambulancia para atender a la abuela paterna de Marta que se encuentra ahora mismo en su casa y está con un ataque de nervios. También hay un equipo de psicólogos que ha venido con ella y está arropando a la familia y atendiéndoles, porque en este momento lo están necesitando más que nunca. También veis que hay policía aquí que está atendiendo gente porque hace escasos minutos una persona, una señora, se ha desmayado de la impresión. Ella venía aquí a poner flores y encender una vela y le ha dado un desmayo de todo lo que está viviendo. La gente está muy impresionada. Esto es lo que estamos notando... $[\ldots]$

\section{Resultados y conclusiones}

Con la transcripción de los fragmentos de las conexiones en directo, de las entrevistas, de los reportajes y de los totales de estos espacios basados en el infoentretenimiento, se puede observar, y asegurar después, que se trata de 
puro entretenimiento disfrazado de aquellos géneros informativos tradicionales conformados por hechos.

Sin ningún género de duda, el profesional de la información va más allá de su cometido al hurgar en lo morboso del hecho noticioso, consiguiendo perder la objetividad que necesita este tipo de informaciones al redactarse.

En el caso de la noticia de la estafa a seiscientas personas por parte de financieras ubicadas en la Comunidad Valenciana, queda patente que el reportero se excede al preguntar el motivo por el que aquella situación llevó a la persona afectada a un intento de suicidio.

La noticia del juicio del presunto sacerdote pederasta se elabora con testimonios morbosos: la madre de una de las víctimas, y no con testimonios técnicos: el abogado defensor, por ejemplo. Cuando la reportera pregunta a la «mamá» (palabra afectiva y emotiva que despierta todavía más el morbo) de una de las niñas qué era lo que le hacía el hombre a su hija, cuánto tiempo duraron los tocamientos y si había más niñas con ella durante los hechos, queda claro que el infoentretenimiento rebasa todos sus límites, convirtiéndose en espectáculo en su sentido más estricto, con la consiguiente pérdida de la objetividad que conlleva este tipo de noticias.

En cuanto al suceso de una mujer maltratada por su ex pareja, la reportera que la entrevista deja que explique detalles morbosos y muy íntimos de los hechos, justo antes de que otro periodista en el plató le pida que cuente cómo salió de aquel horror y cómo decidió tirarse por un puente.

Pero sin duda el suceso que ha llenado horas de emisión en estos magacines televisivos fue la desaparición de la joven sevillana Marta del Castillo. Las conexiones en directo de estos programas matinales con los padres de la joven, con entrevistas a familiares, amigos y personas implicadas en la búsqueda y en el presunto asesinato de la joven, refuerzan más si cabe el planteamiento de la pérdida de la objetividad en la noticia a favor de la espectacularización en el infoentretenimiento, centrada en el lado más morboso de los hechos. De esta forma, hemos podido observar cómo la periodista de TVE preguntaba a los padres de Marta del Castillo si sabían que la actual pareja del presunto asesino estaba embarazada, además de someterles a una sesión de imágenes en las que los amigos de la joven desaparecida pedían que volviera a casa.

A todo este lamentable espectáculo televisivo hay que añadir la constante utilización de adjetivos, adverbios, superlativos y comparativos por parte de los profesionales de la información - sirvan como ejemplos: «terrible noticia», «tremendamente cansado», «tremendamente impactada», «impresionante»...-, que se ven acompañados de rótulos (en pantalla), como por ejemplo: «espeluznante asesinato». Todo ello contribuye al aludido puro entretenimiento disfrazado de información. 
Sin duda nos encontramos en una nueva era de la televisión en la que géneros y formatos se están transformando definitivamente. La información con la opinión y los límites que separan el infoentretenimiento del espectáculo se mezclan con total asiduidad y, por supuesto, impunidad, para retornar después a la información más supuestamente estricta y rigurosa. Por otro lado, el telespectador se ha acostumbrado a ello y no pide explicaciones e incluso clemencia por el desnudo psicológico de los protagonistas de los hechos.

Si la fragmentación definitiva de las audiencias que ya ha provocado la TDT no nos lleva a un mayor control de la calidad informativa y a la distinción parcelada de los géneros y formatos televisivos destinados al infoentretenimiento, y por supuesto a las demás áreas, entraremos en una espiral social en la que todo valdrá y se dará por aceptado desde el momento en que salen por televisión. Y si llegamos a esto, realidad y ficción no se distinguirán, lo que conllevará, de entrada, a una degradación social de consecuencias impredecibles y, en el mejor de los casos, negativas para las nuevas generaciones que empiezan a consumir ese tipo de televisión como algo habitual en sus vidas. La solución a esta previsible problemática deben encontrarla los propios operadores de canales de televisión y el gobierno de turno, pero también es tarea de los profesionales de la información, porque sin duda sus trabajos se convierten en los auténticos ojos de la sociedad.

\section{Referencias}

Cebrián Herreros, Mariano (1992). Géneros informativos audiovisuales: radio, televisión, periodismo gráfico, cine, vídeo. Madrid: Ciencia.

Cebrián Herreros, Mariano (2004a). La información en televisión. Obsesión mercantil y política. Barcelona: Gedisa.

Cebrián Herreros, Mariano (2004b). Modelos de televisión: generalista, temática y convergente con Internet. Barcelona: Paidós.

Díaz Nosty, Bernardo (2006). La huella es el mensaje. En: Tendencias 2006: Medios de Comunicación. El año de la televisión. Madrid: Fundación telefónica.

García Avilés José Alberto (2007). El infoentretenimiento en los informativos líderes de audiencia en la Unión Europea. En: Anàlisi. Quaderns de comunicación $i$ cultura, núm. 35. Bellaterra: Universitat Autònoma de Barcelona, Servei de Publicacions, 47-63.

Kamp, David (1999). The tabloid decade. Vanity Fair, febrero, ${ }^{\circ} 462$. Condé Nast Publications, United States, p. 64-75.

Krúger, Udo Michael (1988): Infos-Infotainment-Entertainment. En Media Perspektiven, $\mathrm{n}^{0} 10$, Programmanalyse, Frankfurt, Alemania, p. 637-663. 
León Gross, Teodoro (2006). La agenda de los noticiarios. En: Tendencias 2006: Medios de Comunicación. El año de la televisión. Madrid, Fundación telefónica.

Marín, Carles (2003). La noticia audiovisual a través de la historia de la televisión. Palma de Mallorca: Calima ediciones.

Marín Lladó, Carles (2004). El lenguaje en los informativos de televisión. Palma de Mallorca: Calima ediciones.

Marín, Carles (2006). Periodismo audiovisual. Información, entretenimiento y tecnologías multimedia. Barcelona: Gedisa.

Oliva, Llúcia y Sitjà, Xavier (2007). Las noticias en televisión. Barcelona: Omega.

Paget, Dereck (1998). No other way to tell it: dramadoc/docudrama on Televisión. Manchester: Manchester University Press.

\section{Referencia de este artículo:}

Marín Lladó, Carles (2012). La pérdida de objetividad en las noticias de los programas de infoentretenimiento en televisión. En: adComunica. Revista Científica de Estrategias, Tendencias e Innovación en Comunicación, $\mathrm{n}^{\circ} 4$. Castellón: Asociación para el Desarrollo de la Comunicación adComunica, Universidad Complutense de Madrid y Universitat Jaume I, 81-98. DOI: http://dx.doi. org/10.6035/2174-0992.2012.4.6 